\title{
Improvement of Foaming and Emulsifying Properties of Gluten by Conjugation with Fructose through Maillard Reaction
}

\author{
SONG Yongling*, QIN Ruiqi, YANG Shaoming, LI Jianghe, WANG Ruolan
}

Provincal Key Laboratory for Transformation and Utilization of Cereal Resource, Henan University of Technology, Zhengzhou 450001, China

\begin{abstract}
Gluten has poor emulsifying and foaming ability due to its amino acid composition. In this study, Maillard reaction was used to improve the emulsifying and foaming properties of gluten. The processing conditions for the preparation of gluten-fructose conjugates were optimized by using Box-Behnken model to achieve optimum foaming and emulsifying activity, respectively. The results showed that glycated gluten exhibited enhanced emulsifying activity compared to native control. The processing conditions for the preparation of gluten-fructose conjugates with optimum emulsifying activity were as follows: the temperature was $48{ }^{\circ} \mathrm{C}$, reaction time was $72 \mathrm{~h}$, and maltose/gluten $(W / W)$ ratio was $125 \%$. Under such condition, the average emulsifying activity was $66.54 \%$, being improved by about 2.5 times compared with that of native control. The Foaming properties of gluten also increased significantly by glycation modification. The optimum conditions of response were as below: the temperature was $48{ }^{\circ} \mathrm{C}$, reaction time was $66 \mathrm{~h}$, and maltose/gluten ratio $(W / W)$ was $110 \%$. Under such condition, the average foaming property was $158.57 \%$, and it was three folds higher than that of the control.
\end{abstract}

Keywords: Gluten; Glycation; Emulsifying activity; Foaming property; Fructose

\section{Introduction}

Gluten protein is an important by-product of wheat starch production, which accounts for about $10 \%-15 \%$ of the wheat flour, and up to $72 \%-85 \%$ of the flour protein ${ }^{[1]}$. Gluten may be regarded as highly nutritious as it contains a small quantity of starch, fat and mineral substances ${ }^{[2-3]}$. Gluten protein has been used as an additive in food, fodder and other industries ${ }^{[4]}$ The enrichment of hydrophobic amino acids (such as glutamic acid, leucine, proline) in gluten protein facilitates the formation of a larger hydrophobic interaction area in gluten protein ${ }^{[5-6]}$. As a result, the solubility, emulsifying and foaming properties of wheat gluten are not desirable and unable to meet the needs for food processing. Therefore, it is of great significance to improve these functional properties of wheat gluten to broaden its scope of application.

Research shows that the functional characteristics such as solubility, emulsifying activity and other features of proteins isolated from rice and soy could be improved effectively through glycation ${ }^{[7-8]}$. However, there is little data on the functional improvement of gluten through conjugation with a reducing sugar. The objective of this study was to improve the functional characteristics of gluten by modification with fructose through Maillard reaction. In the present work, we analyzed and optimized

Received: 2 November 2017 /Accepted: 10 August 2018.

Supported by Natural Science Project of Department of Science \& Technology of Henan Province (172102110009, 162102210194), The open fund of Provincal Key Laboratory for Transformation and Utilization of Cereal Resource of Henan University of Technology (PL2017010).

*Corresponding author. E-mail: yongling80@126.com

CHenan University of Technology 2018

SONG Y L, QIN R Q, YANG S M, et al. Improvement of Foaming and Emulsifying Properties of Gluten by Conjugation with Fructose through Maillard Reaction[J]. Grain \& Oil Science and Technology, 2018, 1(3): 119-125. the reaction conditions of glycation by using the response surface method. Our work will help to promote the use and value of gluten protein in different industries.

\section{Materials and Methods}

\subsection{Materials}

Gluten was obtained from Fengqiu HuaFeng powder Co. (Fengqiu, China), and fructose was purchased from Tianjin Kermel Chemical Reagent Co. Ltd. (Tianjin, China).

\subsection{Preparation for Gluten-fructose Conjugates}

Appropriate amounts gluten was added to $0.05 \mathrm{~mol} / \mathrm{L}$ sodium phosphate buffer with $\mathrm{pH} 12$. The protein concentration of dilute solution samples is $10 \mathrm{mg} / \mathrm{mL}$. Then fructose was added to the wheat gluten solution in certain proportion. The sample solutions were stirred on a magnetic stirrer at room temperature for $2 \mathrm{~h}$ to completely dissolve the mixture. Solutions were then lyophilized by using a freeze dryer (ModelLGJ-10C, Beijing Sihuan Science Instrument Factory, Beijing, China). For each experiment, a control sample was included which contained no fructose. Lyophilized powder was incubated at different temperature under the relative humidity of $79 \%$ provided by saturated $\mathrm{KBr}$. The obtained reaction products were put into refrigerator for preservation until tests. The diagram for the preparation process of gluten-fructose conjugates is shown in Fig. 1.

\subsection{Emulsifying Activity of the Gluten-fructose Conjugates}

Emulsifying activity was evaluated using research methodology previously described by Aoki et al. ${ }^{[9]}$. Samples were dissolved in phosphate buffer solution $(\mathrm{pH} 8,0.05 \mathrm{~mol} / \mathrm{L})$ to obtain a final protein content of $2 \mathrm{mg} / \mathrm{mL}$ with constant stir at 

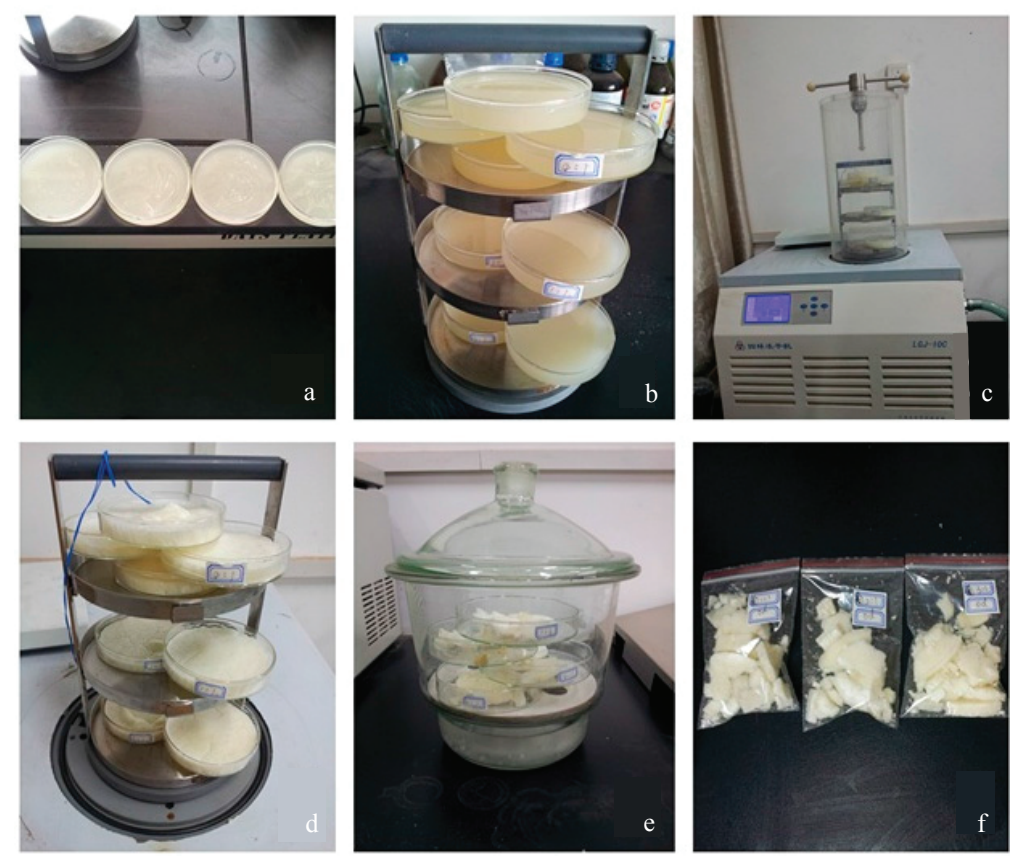

Fig. 1 The preparation process of gluten-fructose conjugates

the ambient temperature. For emulsion formation, soybean oil and the protein solution $(1: 3, V / V)$ were homogenized at $10000 \mathrm{r} / \mathrm{min}$ for $1 \mathrm{~min}$ with an Ultra-Turrax homogenizer (Ika T18 Basic, Staufen, Germany). After homogenization, $50 \mu \mathrm{L}$ of the emulsion was immediately taken from the bottom of the beaker, and diluted to $1: 100$ with $0.1 \%$ SDS solution. The absorbance of diluted emulsion was recorded at $500 \mathrm{~nm}$ using ultraviolet visible spectrophotometer (ModelTU-1810, Beijing Purkinje General Instrument Co. Ltd., Beijing, China).

The emulsifying activity (EA) was expressed in the unit of $\mathrm{m}^{2} / \mathrm{g}$ and calculated with the following equation:

$$
\mathrm{EA}=\frac{2 \times 2.303 \times \mathrm{A} \times \mathrm{DF}}{C \times \theta \times 10000}
$$

Where $2 \times 2.303$ is the conversion factor of interfacial area to light absorption value of lactescence, $\theta$ is the oil volume fraction (0.25), $C$ is the protein concentration $(2 \mathrm{mg} / \mathrm{mL}), \mathrm{DF}$ is the dilution factor (100).

\subsection{Foaming Property of the Gluten-fructose Conjugates}

Foaming property was measured according to the method described by Einhorn-Stoll ${ }^{[10]}$, with slight modification. Lyophilized samples hydration was carried out by dissolving each sample in distilled water $(50 \mathrm{~mL}$ of $1 \% \mathrm{~W} / \mathrm{V}$ protein equivalent, $\mathrm{pH} 7$ ) with a high-speed dispersion homogenizer (ModelFJ200-SH, Shanghai specimen and model factory, Shanghai, China) for $1 \mathrm{~min}$ at $12000 \mathrm{r} / \mathrm{min}$ at room temperature. Subsequently, the sample solution was poured into a $200 \mathrm{~mL}$ measuring cylinder to record the foam volume.

Foaming property $(\%)=$ foam volume $(\mathrm{mL}) / 50(\mathrm{~mL}) \times 100 \%$

\subsection{Experiment Design}

A three-factored $\left(X_{1}, X_{2}\right.$ and $\left.X_{3}\right)$ and three-leveled $(-1,0,1)$ central composite design (CCD) was used to achieve the optimal condition for Maillard reaction (Table 1$)^{[11]}$. The independent variables were reaction temperature $\left(X_{1} /{ }^{\circ} \mathrm{C}\right)$, gluten/ fructose ratio $\left(X_{2} / \%\right)$, and reaction time $\left(X_{3} / \mathrm{d}\right)$, while the dependent variable was emulsifying activity $\left(Y_{1}, \mathrm{~m}^{2} / \mathrm{g}\right)$ and foaming property $\left(Y_{2}, \%\right)$. Replicates were performed for each experiment, and the average values were recorded as the response.

\subsection{Data Analysis}

The data in this experiment was analyzed by using the software of Design-Expert 8.0.6.

\section{Results and Discussion}

\subsection{Results and Analysis of Experiment Design in Response Surface}

The influences of reaction temperature and reaction time on the emulsifying activity and foaming properties in gluten/ fructose ratio $(W / W)$ are shown in Table 2.

The regression analysis were carried out for the data in Table 2 using the analysis software of Design-Expert 8.0.6, and the regression equation is obtained with emulsifying activity $\left(Y_{1}\right)$, foaming property $\left(Y_{2}\right)$, reaction temperature $\left(x_{1}\right)$, gluten/fructose ratio $(W / W)\left(x_{2}\right)$, and reaction time $\left(x_{3}\right)$.

$Y_{1}=62.76-1.89 x_{1}+3.13 x_{2}+12.14 x_{3}-1.78 x_{1} x_{2}-$ $2.50 x_{1} x_{3}+0.63 x_{2} x_{3}-4.91 x_{1}^{2}-4.53 x_{2}^{2}-14.11 x_{3}^{2}$

$Y_{2}=149.44-13.41 x_{1}+8.88 x_{2}+32.44 x_{3}-6.25 x_{1} x_{2}-$ $14.17 x_{1} x_{3}-3.00 x_{2} x_{3}-23.26 x_{1}^{2}-29.08 x_{2}^{2}-51.36 x_{3}^{2}$

The results of the variance analysis are presented in Table 3 and Table 4 . The model $P$ value is smaller than 0.05 for both the emulsifying activity and the foaming property, indicating that the response surface model established is good, with little influence from other factors and sufficient reflection of the relation among these three influence factors and data condition. The multiple 
Table 1 Level and code of experimental factor in response surface

\begin{tabular}{ccccc}
\hline \multirow{2}{*}{ Coded } & Reaction temperature & & Gluten/Fructose $(W / W)$ & \multicolumn{2}{c}{ Reaction time } & $x_{3}(\mathrm{~d})$ \\
\cline { 2 - 3 } & $x_{1}\left({ }^{\circ} \mathrm{C}\right)$ & $x_{2}(\%)$ & 0 \\
0 & 45 & 50 & 2 \\
1 & 50 & 100 & 4 \\
\hline
\end{tabular}

Table 2 Conditions and results in response surface design

\begin{tabular}{cccccc}
\hline Run & $x_{1}\left({ }^{\circ} \mathrm{C}\right)$ & $x_{2}(\%)$ & $x_{3}(\mathrm{~d})$ & Emulsifying activity $\left(\mathrm{m}^{2} / \mathrm{g}\right)$ & Foaming property $(\%)$ \\
\hline 1 & 55 & 100 & 4 & 50.4 & 80.7 \\
2 & 50 & 50 & 0 & 30.1 & 30.7 \\
3 & 50 & 100 & 2 & 65.4 & 147.8 \\
4 & 50 & 100 & 2 & 63.6 & 149.1 \\
5 & 45 & 150 & 2 & 60.5 & 40.6 \\
6 & 45 & 100 & 0 & 32.1 & 154.9 \\
7 & 50 & 100 & 2 & 60.5 & 150.2 \\
8 & 50 & 100 & 2 & 63.1 & 46.8 \\
9 & 50 & 150 & 0 & 33.0 & 106.3 \\
10 & 50 & 150 & 4 & 59.4 & 93.3 \\
11 & 55 & 150 & 2 & 54.5 & 145.2 \\
12 & 50 & 100 & 2 & 61.2 & 97.2 \\
13 & 50 & 50 & 4 & 54.0 & 138.2 \\
14 & 55 & 100 & 0 & 32.0 & 78.4 \\
15 & 45 & 100 & 4 & 60.5 & 90.4 \\
16 & 55 & 50 & 2 & 49.7 & \\
17 & 45 & 50 & 2 & 48.6 & \\
\hline
\end{tabular}

Table 3 Variance analysis of emulsifying activity

\begin{tabular}{|c|c|c|c|c|c|c|}
\hline Source & Sum of squares & $\mathrm{d} f$ & Mean square & $F$ value & $P$ value & \\
\hline Model & 2428.8502 & 9 & 269.8722 & 64.7076 & $<0.0001$ & significant \\
\hline A-reaction temperature & 28.5013 & 1 & 28.5013 & 6.8338 & 0.0347 & \\
\hline B-gluten/fructose & 78.1250 & 1 & 78.1250 & 18.7321 & 0.0034 & \\
\hline C-reaction time & 1178.5513 & 1 & 1178.5513 & 282.5826 & $<0.0001$ & \\
\hline $\mathrm{AB}$ & 12.6025 & 1 & 12.6025 & 3.0217 & 0.1257 & \\
\hline $\mathrm{AC}$ & 25.0000 & 1 & 25.0000 & 5.9943 & 0.0442 & \\
\hline $\mathrm{BC}$ & 1.5625 & 1 & 1.5625 & 0.3746 & 0.5598 & \\
\hline $\mathrm{A}^{2}$ & 101.3012 & 1 & 101.3012 & 24.2891 & 0.0017 & \\
\hline $\mathrm{B}^{2}$ & 86.4038 & 1 & 86.4038 & 20.7171 & 0.0026 & \\
\hline $\mathrm{C}^{2}$ & 837.6885 & 1 & 837.6885 & 200.8536 & $<0.0001$ & \\
\hline Residual & 29.1945 & 7 & 4.1706 & & & \\
\hline Lack of fit & 13.8625 & 3 & 4.6208 & 1.2055 & 0.4151 & not significant \\
\hline Pure error & 15.3320 & 4 & 3.8330 & & & \\
\hline Cor total & 2458.0447 & 16 & & & & \\
\hline
\end{tabular}

correlation coefficients of emulsifying activity and foaming properties were both greater than 0.8 , which further verified the establish model could be used to analyze and predict the experiment.

\subsection{Response Surface Analysis}

Each factor was fixed to zero level respectively, and the response surface models stablished on the interactions between the other two factors were obtained. The results are shown in Fig. 2 and Fig. 3.

Fig. 2a shows the steep of the response surface are similar along the direction of the reaction temperature and the gluten/fructose ratio $(W / W)$. This proves that the reaction temperature and the gluten/fructose ratio $(W / W)$ have similar impact on the emulsifying activity of the gluten-fructose conjugates. And the effects are significant. But the interaction of the two factors on the influence of emulsifying activity is not obvious. The emulsifying activity of the gluten-fructose conjugates has a peak when the reaction temperature is $48.05^{\circ} \mathrm{C}$ and the gluten/fructose ratio $(W / W)$ is $122.8 \%$. Fig. $2 \mathrm{~b}$ shows the response surface is steeper along the direction of the reaction temperature than that along the direction of the gluten/fructose ratio $(W / W)$. This demonstrates that the reaction time has significant effect on the emulsifying activity of the gluten-fructose conjugates. The gluten-fructose conjugates have the highest emulsifying activity when the reaction time is $2.95 \mathrm{~d}$ and the reaction temperature is $48.05^{\circ} \mathrm{C}$. 
Table 4 Variance analysis of foaming property

\begin{tabular}{crrrrrr}
\hline Source & Sum of squares & $\mathrm{d} f$ & Mean square & \multicolumn{1}{c}{$F$ value } & \multicolumn{1}{c}{$P$ value } \\
\hline Model & 30140.8979 & 9 & 3348.9887 & 128.8891 & $<0.000$ & significant \\
A-reaction temperature & 1386.0113 & 1 & 1386.0113 & 53.3420 & 0.0002 & 0.0010 \\
B-gluten/fructose & 760.5000 & 1 & 760.5000 & 29.2686 & $<0.0001$ \\
C-reaction time & 8745.0313 & 1 & 8745.0313 & 336.5609 & 5.0898 & 0.0587 \\
AB & 132.2500 & 1 & 132.2500 & 30.9320 & 0.0008 \\
AC & 803.7225 & 1 & 803.7225 & 0.4715 & 0.5144 \\
BC & 12.2500 & 1 & 12.2500 & 90.5020 & $<0.0001$ \\
A $^{2}$ & 2351.5581 & 1 & 2351.5581 & 128.9341 & $<0.0001$ \\
B $^{2}$ & 3350.1602 & 1 & 3350.1602 & 421.1929 & $<0.0001$ \\
C $^{2}$ & 10944.0644 & 1 & 10944.0644 & & 0.1337 \\
Residual & 181.8844 & 7 & 25.9835 & & not significant \\
Lack of fit & 130.7125 & 3 & 43.5708 & 3.4058 & & \\
Pure error & 51.1720 & 4 & 12.7930 & & & \\
Cor total & 30322.7824 & 16 & & &
\end{tabular}

Fig. 2c shows that when the reaction time is fixed, the emulsifying activity increased with the increase of the gluten/fructose ratio $(W / W)$ slightly. When the gluten/fructose ratio $(W / W)$ is fixed, the emulsifying activity also increased with the increase of the reaction time. And after reaction to a certain time, the emulsifying activity begins to decrease.

When the reaction time and the gluten/fructose ratio $(W / W)$ are $2.95 \mathrm{~d}$ and $122.8 \%$ respectively, the gluten-fructose conjugates have the highest emulsifying activity. This is because part of the protein expanded and unfolded at the early stage of the reaction, fructose and protein gradually combined with heating lead to the ability of emulsification as well as the surface activity enhance. As the reaction time prolonged, protein and fructose became more and more hydrophilic. This reduced the interfacial activity, thereby leading to reduced emulsification activity ${ }^{[12]}$.

The results show that the most significant factor on the emulsifying activity of the gluten-fructose conjugates is the reaction time through the analysis of interaction of the three factors. When the reaction temperature and the gluten/fructose ratio $(W / W)$ are fixed, the emulsifying activity increases at first and then decreases with the increase of the reaction time.

Fig. 3a shows the response surface points downwards and the surface is flat. At the same time, the steep of the response surface are similar along the direction of the reaction temperature and the gluten/fructose ratio $(W / W)$. This suggests that the effect of the interaction between the reaction temperature and the gluten/fructose ratio $(W / W)$ on the foaming property of the gluten-fructose conjugates is not significant. The gluten-fructose conjugates have the highest foaming property when the gluten/fructose ratio $(W / W)$ is $108.92 \%$ and the reaction temperature is $47.88^{\circ} \mathrm{C}$. Fig. $3 \mathrm{~b}$ shows the foaming property increases at first and then descends with the reaction temperature increasing when the reaction time is fixed. When the reaction temperature is fixed, the foaming property has similar trend. The gluten-fructose conjugates have the highest foaming property when the reaction time is $2.75 \mathrm{~d}$ and the reaction temperature is $47.88^{\circ} \mathrm{C}$. Fig. $3 \mathrm{c}$ shows the steep of the response surface is bigger, demonstrating that the reaction time and the reaction temperature have significant effect on the foaming property of the gluten-fructose conjugates. And the response surface is steeper along the direction of the reaction time than that along the direction of the gluten/fructose ratio $(W / W)$. This proves the effect of the reaction time on foaming property is more significant. The gluten-fructose conjugates have the highest foaming property when the reaction time is $2.75 \mathrm{~d}$ and the gluten/fructose ratio $(W / W)$ is $108.92 \%$.

\subsection{Process Optimization and Experimental Verification}

The glycation process was optimized by using the Box-Behnken model. The optimal reaction condition for enhancing emulsifying activity was as follows: the reaction temperature was $48.05{ }^{\circ} \mathrm{C}$, the gluten/fructose ratio $(W / W)$ was $122.8 \%$, and the reaction time was $2.95 \mathrm{~d}$. For practical application, the reaction condition was adjusted as below: the reaction temperature was $48{ }^{\circ} \mathrm{C}$, the gluten/fructose ratio $(W / W)$ was $125 \%$, and the reaction time was $3 \mathrm{~d}(72 \mathrm{~h})$. Under these conditions, three groups of validation tests were made. The emulsifying activity of the gluten-fructose conjugates were $66.75,66.91,65.96 \mathrm{~m}^{2} / \mathrm{g}$, respectively. The average value was $66.54 \mathrm{~m}^{2} / \mathrm{g}$ with the standard error of 0.29 , the average value being similar to the theoretical value of $66.73 \mathrm{~m}^{2} / \mathrm{g}$. The variance of the theoretical value was within $1 \%$ of the measured value, justifying the accuracy of the regression equation.

The optimal reaction condition for foaming property was as below: reaction temperature was $47.88^{\circ} \mathrm{C}$, the gluten/fructose ratio $(W / W)$ was $108.92 \%$, and the reaction time was $2.74 \mathrm{~d}$. In practice, the reaction condition was adjusted as below: the reaction temperature is $48{ }^{\circ} \mathrm{C}$, the gluten/fructose ratio $(W / W)$ is $110 \%$, and the reaction time is $2.75 \mathrm{~d}(66 \mathrm{~h})$. Under these conditions, three parallel tests were performed, and the foaming property was $157.6 \%, 159.0 \%$ and $159.1 \%$ respectively. The average value was $158.57 \%$ with the standard error of 0.31 , the average value is almost equivalent to the theoretical value of $159.07 \%$. The variance of the theoretical value was within $1 \%$ of the measured value, validating the accuracy of the regression equation.

\section{Conclusions}

(1) The established response surface models for emulsifying activity and foaming properties are good and predictive, having insignificant lack of fit and theoretical data being consistent with experimental data. 


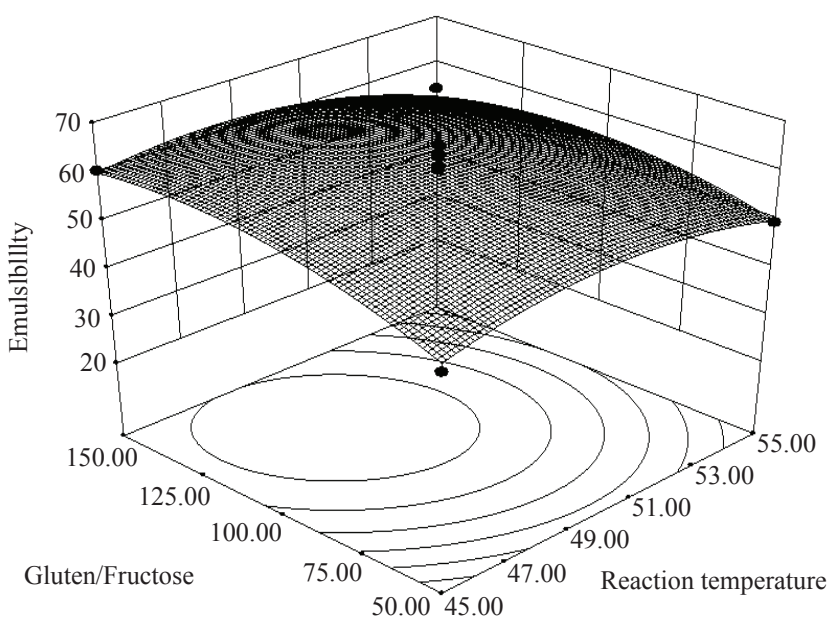

a. Response surface of emulsifying property under the gluten/fructose ratio and the reaction temperature

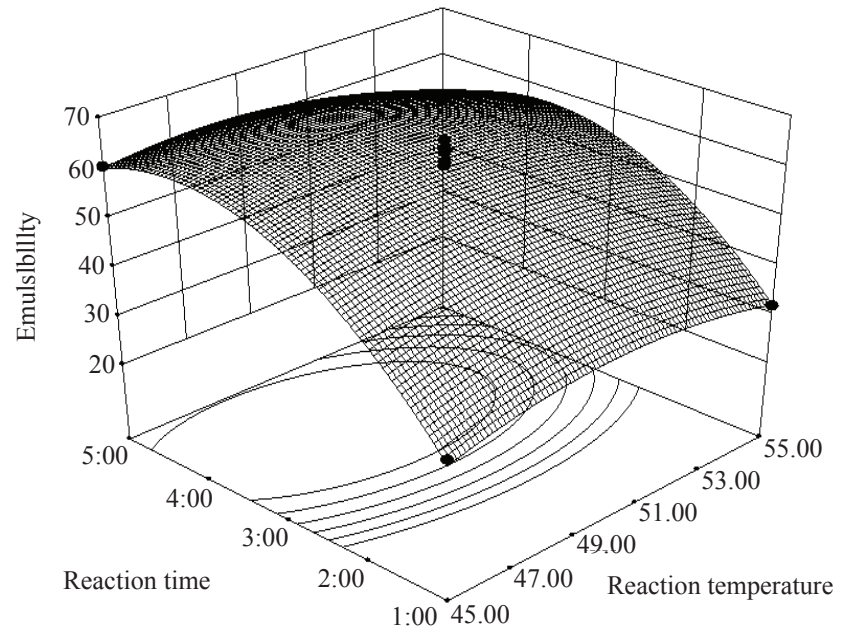

b. Response surface of emulsifying property under the reaction time and the reaction temperature

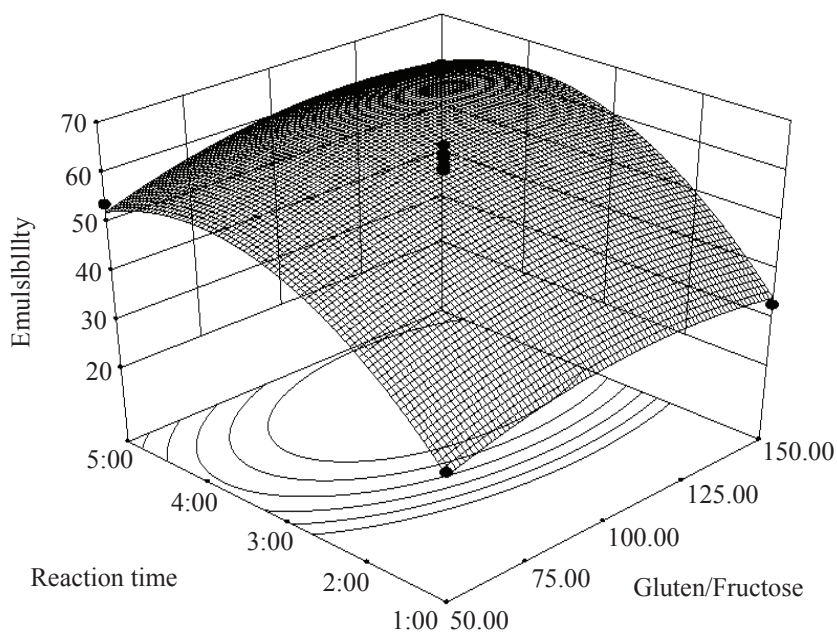

c. Response surface of emulsifying property under the reaction time and the gluten/fructose ratio

Fig. 2 Response surface analysis of interaction between two factors in emulsifying activity 


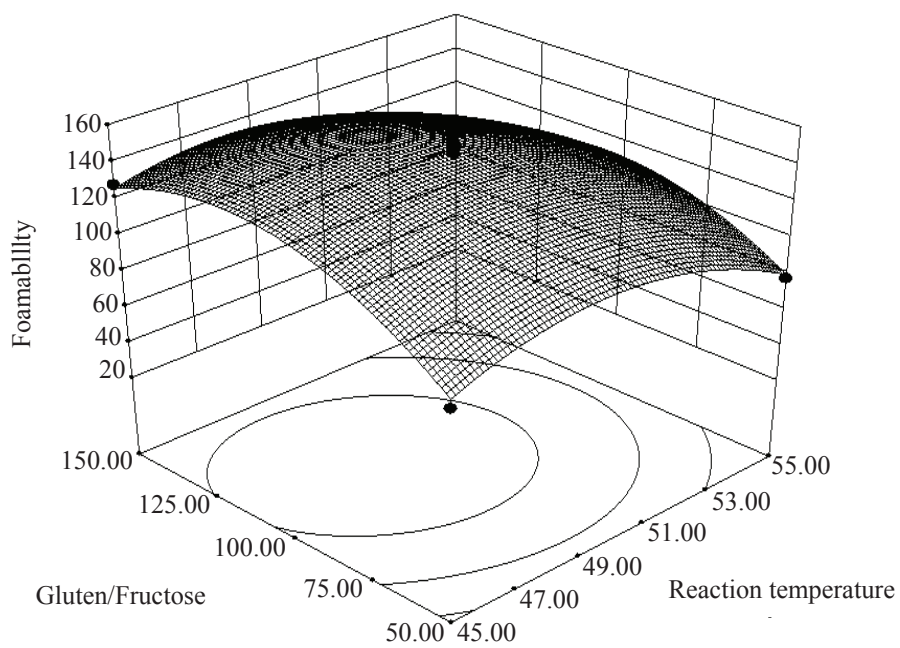

a. Response surface of foaming property under the gluten/fructose ratio and the reaction temperature

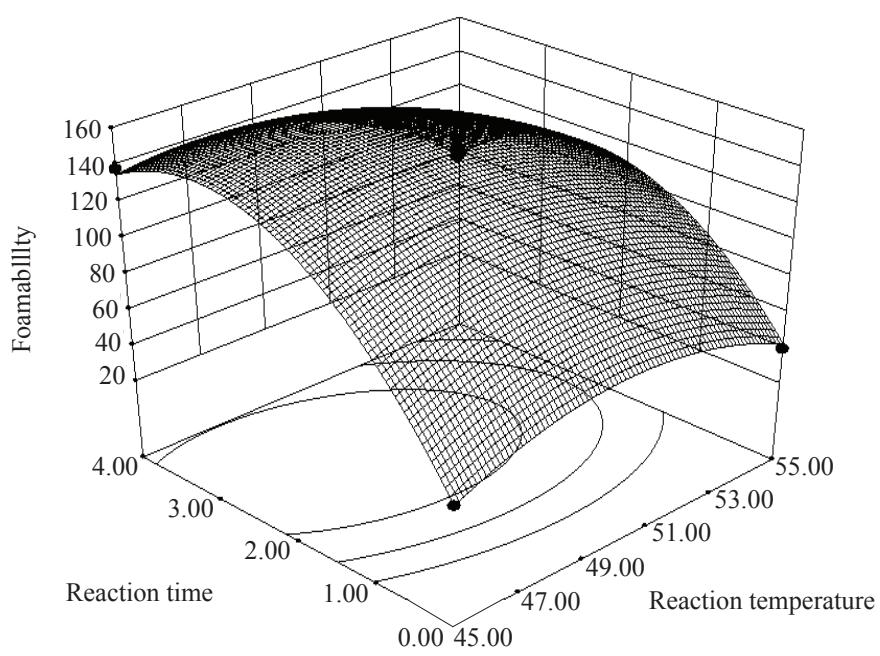

b. Response surface of foaming property under the reaction time and the reaction temperature

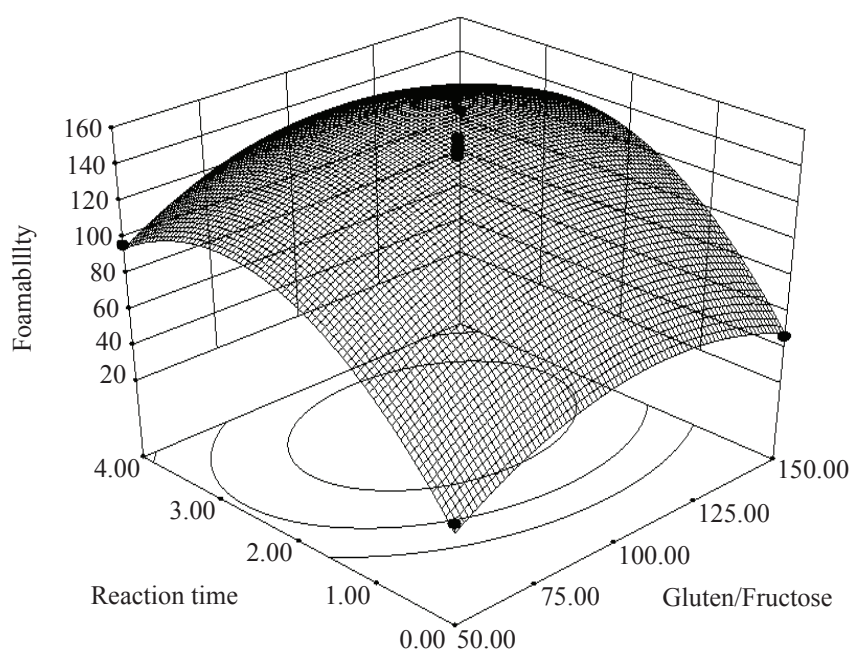

c. Response surface of foaming property under the reaction time and the gluten/fructose ratio

Fig. 3 Response surface analysis of interaction between two factors in foaming property 
(2) As far as the emulsifying activity of the gluten-fructose conjugates is concerned, the reaction condition after optimization are as below: the reaction temperature is $48{ }^{\circ} \mathrm{C}$, the gluten/fructose ratio $(W / W)$ is $125 \%$, and the reaction time is $3 \mathrm{~d}(72 \mathrm{~h})$. The average value of emulsifying activity under this condition is $66.54 \mathrm{~m}^{2} / \mathrm{g}$, which is about 2.5 times higher compares with that of natural gluten.

(3) As for the foaming property of the gluten-fructose conjugates, the reaction condition after optimization are as below: the reaction temperature is $48^{\circ} \mathrm{C}$, the gluten/fructose ratio $(W / W)$ is $110 \%$, and the reaction time is $2.75 \mathrm{~d}(66 \mathrm{~h})$. The average foaming property at these conditions is $158.57 \%$, which is about 3 times higher than that of natural gluten.

\section{Conflict of Interest}

The authors declare that there is no conflict of interest.

\section{References}

[1] SCHERF K A, WIESER H, KOEHLER P. Novel approaches for enzymatic gluten degradation to create high-quality gluten-free products[J]. Food Research International, 2018, 110: 62-72.

[2] CERESINO E B, KUKTAITE R, SATO H H, et al. Impact of gluten separation process and transglutaminase source on gluten based dough properties[J]. Food Hydrocolloids, 2019, 87: 661-669.

[3] SCHERF K A, KOEHLER P, WIESER H. Gluten and wheat sensitivities-An overview[J]. Journal of Cereal Science, 2016, 67: 2-21.

[4] WANG P, ZOU M, TIAN M Q, et al. The impact of heating on the unfolding and polymerization process of frozen-stored gluten[J]. Food Hydrocolloids, 2018, 85: 195-203.

[5] AGYARE K K, XIONG Y L, ADDO K. Influence of salt and $\mathrm{pH}$ on the solubility and structural characteristics of transglutaminase-treated wheat gluten hydrolysate[J]. Food Chemistry, 2008, 107(3): 1131-1137.

[6] KIEFFER R, SCHURER F, KöHLER P, et al. Effect of hydrostatic pressure and temperature on the chemical and functional properties of wheat gluten: Studies on gluten, gliadin and glutenin[J]. Journal of Cereal Science, 2007, 45(3): 285-292.

[7] YA L L, FENG H, ZHENG T Y, et al. The growth of N-doped carbon nanotube arrays on sintered $\mathrm{Al}_{2} \mathrm{O}_{3}$ substrates[J]. Materials Science and Engineering B, 2009, 158: 69-74.

[8] XUE F, LI C, ZHU X W. Comparative studies on the physicochemical properties of soy protein isolate-maltodextrin and soy protein isolate-gum acacia conjugate prepared through Maillard reaction[J]. Food Research International, 2013, 51: 490-495.

[9] AOKI T, HIIDOME Y, KITAHATA K, et al. Improvement of heat stability and emulsifying activity of ovalbumin by conjugation with glucuronic acid through the Maillard reaction[J]. Food Research International, 1999, 32: 129-133.

[10] STOLL, U E; ULBRICH, M, SEVER, S, et al. Formation of milk protein-pectin conjugates with improved mulsifying properties by controlled dry heating[J]. Food Hydrocolloids, 2005, 19: 329-340

[11] YEBOAH F K, ALLI I, YAYLAYAN V A. Reactivies of $\mathrm{D}$-glucose and D-fructose during glycation of bovine serum albumin[J]. Journal of Agricultural and Food Chemistry, 1999, 47: 3164-3172.

[12] MARTINEZ-ALVARENGA M S, MARTINEZ-RODRIGUEZ E Y, GARACIA-AMEZQUITAL L E, et al. Effect of Maillard reaction conditions on the degree of glycation and functional properties of whey protein isolate Malto dextrin conjugates $[\mathrm{J}]$. Food Hydrocolloids, 2014, 38: 110-118. 